International Journal of Current Microbiology and Applied Sciences

ISSN: 2319-7706 Volume 9 Number 7 (2020)

Journal homepage: http://www.ijcmas.com

\title{
Evaluation of CD68 in Oral Squamous Cell Carcinoma and their Relation with Clinicopathological Parameters -An Immunohistochemical Study
}

\author{
Ahlam T. Bdewi ${ }^{1}$, Ahmed A. Alkadir Mohamed Labib ${ }^{2}$, Ban F. AL Drobie ${ }^{3}$, \\ Bashar H. Abdullah ${ }^{3}$ and Museedi Omar ${ }^{3}$ \\ ${ }^{1}$ Department of Oral Diagnosis/ College of Dentistry /Al Anbar University,Iraq \\ ${ }^{2}$ Department of Clinical Oncology/, Clinical Oncologist, Al-Amal Hospital, Baghdad, Iraq \\ ${ }^{3}$ Department of Oral Diagnosis/ Oral Pathology, College of Dentistry, \\ Baghdad University, Iraq \\ *Corresponding author
}

\section{A B S T R A C T}

\section{Keywords \\ Oral Squamous Cell Carcinoma, CD68 \\ Immuno- \\ histochemical Study}

Article Info

Accepted:

22 June 2020

Available Online:

10 July 2020

\begin{abstract}
Macrophages are important cells for the innate immunity. Circulating monocytes are attracted to tissues by chemotactic factors and become macrophages under the influence of their microenvironment. Several studies have shown that macrophages are important to the prognosis of patients with different types of cancer. The aim of this study was to evaluate the expression of CD68 in OSCC patients and to investigate the possible relationship of macrophages using CD68 in various histopathological grades, stages and other clinical parameters of OSCC. preoperative diagnosed specimens $(n=30)$ were processed for immunohistochemistry to detect CD68 positive cells. Expression of macrophages was semiquantitatively analyzed. Immunohistochemical study show expression of CD68 in all specimens. A significant correlation between CD68 infiltration and gender of patients was found, where it high in females than males. Other clinicopathological findings of OSCC show non-significant correlation. Immunohistochemical expression of CD68 were observed in all studying samples of oral squamous cell carcinoma. however, statistically non-significant correlation was found between the mean expression level of these infiltrates macrophages with clinicopathological findings of OSCC expect with Gender.
\end{abstract}

\section{Introduction}

Oral squamous cell carcinoma (OSCC) accounts for about $90 \%$ of all oral neoplasms (1). Despite advanced therapeutic approaches, the 5 years survival rate of patients with OSCC remains $<50 \%$, mainly due to the presence of regional lymph node metastasis (2).
Like other cancer types, OSCC have a complex tumor microenvironment (TME) with the presence of several stromal cells that might be associated to tumor aggressiveness and the resistance and failure to antineoplastic treatment $(4,5)$.

Among immune cells, tumor-associated macrophages (TAMs) are the most abundant 
and important stromal cells in the TME (6). TAMs are considered important players in tumor progression and are related to proliferation and survival of tumor cells, angiogenesis, invasion of surrounding tissues and metastasis (7).

Tumor microenvironment is a complex system where tumor cells reprogram stromal cells for their own benefit. From the ten hallmarks of cancer described by Hanahan and Weinberg (2011), these reprogramed cells contribute to at least seven hallmarks: sustaining proliferative signaling, evading growth suppressors, avoiding immune destruction, deregulating cellular energetics, resisting cell death, inducing angiogenesis and activating invasion and metastasis. For instance, during oral squamous cell carcinoma progression, the reprograming of stromal cells already starts in potentially malignant disorders, where altered non-neoplastic cells induce angiogenesis and modifications in immune cells in the adjacent connective tissue. When these altered non-neoplastic cells become malignant cells and invade adjacent connective tissue shortly after basal membrane rupture, there is switch to an immunosuppressive TME, which allows tumor development.

Macrophages, which derive from circulating monocytes, play an important role in innate immunity and adaptive immunity [9-10]. Importantly, CD68 has been widely used as a pan macrophage marker in over $80 \%$ of studies. Several reports found that the presence of CD68 + TAMs was associated with decreased 5-year survival rates in several cancer including thyroid, lung, hepatocellular and esophageal cancers [11.12]. But some studies showed that no significant associations were found between the percentage of CD68 + TAM and survival time for OSCC patients.
It had been reported that the presence of CD68 + TAMs in tumor nest promoted tumor progression and was related to poor prognosis in hepatocellular cancer patients [13]. Infiltration of CD68 + macrophages in breast tumor stroma were positively associated to tumor size and were an independent prognostic factor (14).

Here, we focused on the expression of of CD68 + TAMs in OSCC and analyzed the correlations of expression of CD68 + TAM with the clinicopathological parameters.

\section{Materials and Methods}

\section{Patients and tissue sample}

In this retrospective study, OSCC tissue specimens from 30 patients were obtained from the archive department of oral diagnosis, Collage of Dentistry, Baghdad University. The study protocol was approved by the ethical committee. The specimens used in this study were obtained from tissue samples collected for routine histopathological diagnosis, where the diagnosis of OSCC was based on histologic examination of hematoxylene and eosin-stained tissue sections. Specimens were obtained from total surgical excision of the lesions. The clinical data (age, gender, tumor location and size) were obtained from medical records.

\section{Immunohistochemical staining}

The formaline -fixed,paraffine -embeded tissue samples were sliced into $4 \mathrm{~mm}$ thickness with a rotation microtome. Immunohistochemical staining was performed using peroxidased-labeled streptavidin-biotin technique. Briefly, tissue sections were dewaxed in xylole and rehydrate in graded alcohol and heated in metal slide holder containing citrate buffer (pH6.0) at 95C for 20 minutes to retrieve antigenicity. Then 
sections treated with $\mathrm{H} 2 \mathrm{O} 2$ for 10 minutes to quench endogenous peroxidase activity. Then treated with protein block to block nonspecific binding. After washing in $10 \mathrm{~mm}$ PBS, sections were incubated with following primary antibodies: monoclonal mouse anti human CD68 (clone KP1 + C68/684; ab199000; abcam, Cambridge, UK) at $0.5 / 500$, at 37 degree for 1 hour and overnight incubation at in humidified chamber. After washing, sections were treated with mouse and rabbit specific HRP/DAB detection system (ab236466, abcam, Cambridge, UK). Finally, the sections were stained with Mayers hematoxylene and covered. Samples of lymph node were used as positive control for marker. Negative control were obtained by omitting the primary antibodies.

\section{Statistical analysis}

The data analyzed using Statistical Package for Social Sciences (SPSS) version 25. The data presented as mean, standard deviation and ranges. Categorical data presented by frequencies and percentages. Independent ttest and Analysis of Variance (ANOVA) (two tailed) was used to compare the continuous variables accordingly. A level of $\mathrm{P}-$ value less than 0.05 was considered significant.

\section{Results and Discussion}

\section{Patient Characteristics}

The clinico-pathological characteristics of all of the patients are summarized in Table.1.

Study patients' age was ranging from 22 to 85 years with a mean of 55.6 years and a standard deviation of \pm 14.7 years. We noticed that the highest proportion of study patients was aged > 50 years $(63.3 \%$. (Regarding gender, proportion of males was higher than females (63.3\% versus $36.7 \%$ ) with a male to female ratio of $1.7: 1$
In this study, the lesions were staged IV in $60 \%$ of case. Regarding grading, $56.7 \%$ of lesions were well differentiated.

Concerning site of lesion, the most common site of lesion detected was the tongue $(36.6 \%)$.

\section{Immunohistochemical Analysis}

To evaluate the CD68 antibodies expression we considered positive all cells that exhibited brownish color, regardless of the intensity in the cytoplasmic or nuclear region. Therefore, the CD86 expression was examined by two independent researchers using light microscope Olympus CH30 (Olympus Japan Co, Tokyo, Japan). The percentage of immunopositive cells for marker was recorded semi-quantitatively, in the inflammatory infiltrate of the invasion front, in consecutive fields to the full extent. Thus, analysis of the percentage of macrophages was classified as follows: 0 when less than $10 \%$; 1 between $11 \%-50 \%$; and 2 and when greater than $50 \%$.

To determine the type of infiltrated immune cells in OSCC, we performed an immunohistochemical analysis using antibodies against lineage-specific marker CD68 for all macrophages. In the current study, the immunohistochemical analysis demonstrated that CD68 + cells were observed in all grades of tumor specimens (Figure1). The CD68 + macrophages were distributed in the tumor stroma. There was a non-significant increased in number of macrophage in poorly differentiated cases compared with well and moderate differentiated cases (mean of total CD68 score 43.3, 36.0 and 37.0 respectively). However, statistically non signifacnt correlation was observed between the number of infiltrating CD68 + cells and the histological grade of the tumor as seen in table (2). 
Table.1 Clinicopathological characterstic of patient with OSCC

\begin{tabular}{|l|c|c|c|}
\hline \multicolumn{1}{|c|}{ Variable } & No. $(\mathbf{n}=\mathbf{3 0})$ & Percentage (\%) \\
\hline Age & & 19 & 63.3 \\
\hline Gender & $\mathbf{5 0}$ & 11 & 36.6 \\
\hline & Male & & 63.3 \\
\hline Staging & Female & 19 & 36.6 \\
\hline & I & 11 & 6.7 \\
\hline II & 2 & 13.3 \\
\hline III & 4 & 20.0 \\
\hline Grading (Differentiation) & 6 & 60.0 \\
\hline Well & 18 & \\
\hline Moderate & 17 & 56.7 \\
\hline Site of lesion & Poor & 10 & 33.3 \\
\hline Tongue & 3 & 10.0 \\
\hline Cheek & 11 & 36.6 \\
\hline Jaw & 5 & 16.6 \\
\hline Floor of mouth & 5 & 16.6 \\
\hline Oral cavity & 4 & 13.3 \\
\hline Lip & 3 & 10.0 \\
\hline
\end{tabular}

Table.2 Comparison in mean of total CD68 score percentage according to clinic-pathological characteristics

\begin{tabular}{|c|c|c|}
\hline Variable & $\begin{array}{l}\text { Total CD68 score (\%) } \\
\text { Mean } \pm \text { SD }\end{array}$ & P - Value \\
\hline \multicolumn{3}{|l|}{ Age (Years) } \\
\hline$\leq \mathbf{5 0}$ & $39.5 \pm 6.9$ & \multirow[t]{2}{*}{0.098} \\
\hline$>\mathbf{5 0}$ & $35.7 \pm 5.4$ & \\
\hline \multicolumn{3}{|l|}{ Gender } \\
\hline Male & $35.2 \pm 5.6$ & \multirow[t]{2}{*}{0.023} \\
\hline Female & $40.4 \pm 5.9$ & \\
\hline \multicolumn{3}{|l|}{ Stage } \\
\hline I & $33.8 \pm 12.9$ & \multirow{4}{*}{0.667} \\
\hline II & $34.9 \pm 3.7$ & \\
\hline III & $36.5 \pm 6.9$ & \\
\hline IV & $38.1 \pm 5.9$ & \\
\hline \multicolumn{3}{|l|}{ Grade } \\
\hline Well & $36.0 \pm 5.3$ & \multirow[t]{3}{*}{0.168} \\
\hline Moderate & $37.0 \pm 7.0$ & \\
\hline Poor & $43.3 \pm 6.1$ & \\
\hline
\end{tabular}


Fig.1 Immunohistochemical staining of OSCC with anti-CD68 antibodies in different pathological grades (A) grade I, (B) grade II and (C)grade III (original magnification 100x). The marker shows a cytoplasmic staining. The shape of staining cells include predominately round cells, but some show spindle shape. Beside macrophage staining, in most cases pale staining of epithelial cells detectable include tumor cells. Magnified figures (Original magnification 400x) are shown in the bottom right hand corner of all figures
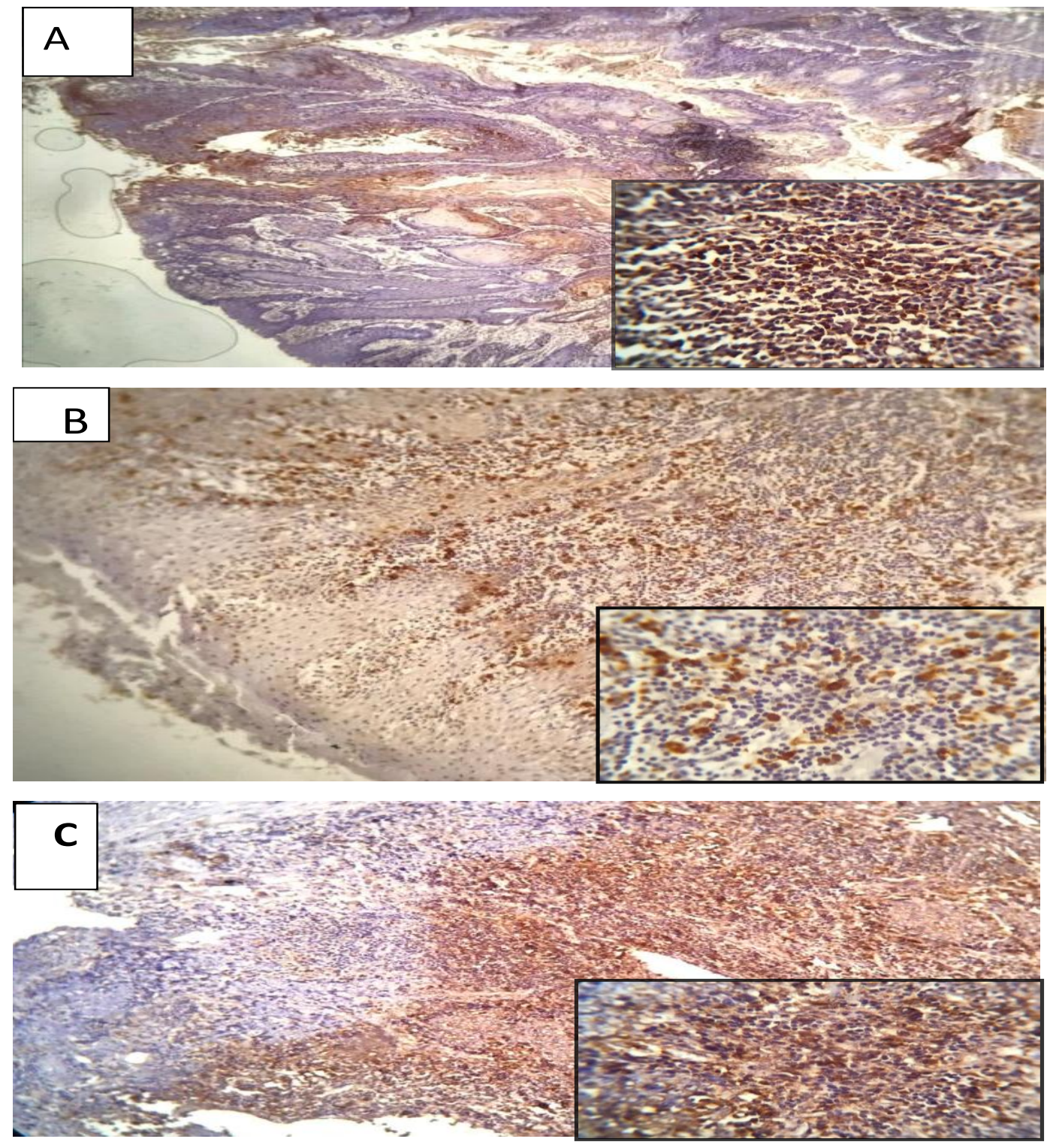

The present study found that, there is correlation between number of macrophage and gender. The number of macrophage were significantaly more increased in females than males. Although it was not significant, there is a positive correlation between the number of cell and the stage of tumor, where the higher number of positive cell were in stage IV.

The tumor-associated macrophage is a predominant cellular component for the tumor microenvironment in various tumors. Although previous studies have demonstrated 
that TAMs are detected in OSCC $[15,16]$, whether these TAMs have the M1 or M2 phenotype is poorly understood. In the present study, we evaluated surgically dissected specimens from 30 OSCCs using an immunohistochemical analysis with the antiCD68 antibody, which is a marker for macrophages $[17,18]$. The results demonstrate that many macrophages are detected in OSCC.

In this study, TAMs were observed in all cases analyzed, distributed in the tumor parenchyma, findings also observed by ElRouby (16) and Liu et al., (22), suggesting the recruitment of these cells towards the tumor region and the consequent ability to modify the neoplastic process. In our study, numerous macrophages were observed along the invasion front, which indicates that such cells play an important role in the recognition and destruction of the tumor. Statically nonsignificant correlation was found with clinical parameters except gender, where its expressed increased in number of macrophage in female more than males. This result disagree with, $\mathrm{Li}$ C. and colleagues in 2002(19) who identified that tumoral accumulation of macrophages is associated with stage of invasion. Sica and colleagues in 2006 (20) reported predominance of the macrophage population in the peritumoral infiltrate in OSCC. On other hand, present finding was in the same line with Kazumasa and colleagues in 2011 (21), who found non significant statistical difference between infiltrated macrophages and the pathological grade and stage of OSCC. In many immunohistochemical studies, it was observed that the number of TAMs CD68 positive was associated with OSCC specimen prognosis. Lu et al., (23) found that a significantly higher number of CD68 positive macrophages was observed in larger tumors, recurrent, with lymph node metastasis and advanced clinical stages. He et al., (24) found that CD68 expression were significantly associated with the presence of lymph node metastasis. The reasons for these results were difficult to explain, because macrophage cells include M1, M2 and undifferentiated monocytes/macrophages, it is likely that these mixed cell populations are functionally heterogeneous regarding the development and progression of OSCC. Accumulation of macrophages $\mathrm{M} 1, \mathrm{M} 2$ in response to tumor cell- derived signals, either because of tumor selection and evolution or as part of anti-tumor responses of the host, is diverted to pro-tumorigenic responses by stimulate tumor growth and invasion through enhanced cell proliferation mediated through the production of TNFa, IL-6, and other cytokines (21).

In conclusion the results of this study indicate that macrophages are important cells in the development and progression of the SCC, since they were present in all cases analyzed and the number of macrophage was increased in poor differentiated cases but statistically non-significant correlation was found between the mean expression level of these infiltrates with clinicopathological findings of OSCC except with the gender where it expressed high infiltration in female than male. however further studies with larger samples needed to identify their exact correlation with clinicopathological features of tumor.

\section{References}

1. Perdomo S, Martin Roa G, Brennan P, Forman D, Sierra MS. Head and neck cancer burden and preventive measures in Central and South America. Cancer Epidemiol. 2016; 44 Suppl 1:S43-s52.

2. Angela C. Chi., et al., Oral Cavity and Oropharngeal Squamous Cell Carcinoma-An update. A cancer J.2015; $65,5$.

3. Curry JM, Sprandio J, Cognetti D, et al., 
Tumor microenvironment in head and neck squamous cell carcinoma. Semin Oncol. 2014; 41 (2):217-234.

4.. Gildener-Leapman N, Ferris RL, Bauman JE. Promising systemic immunotherapies in head and neck squamous cell carcinoma. Oral Oncol. 2013;49 (12):1089-1096.

5.. Mantovani A, Allavena P. The interaction of anticancer therapies with tumor associated macrophages. J Exp Med. 2015;212(4):435-445.

6. Galdiero MR, Garlanda C, Jaillon S, Marone G, Mantovani A. Tumor associated macrophages and neutrophils in tumor progression. J Cell Physiol. 2013; 228 (7):1404-1412.

7. Ruffell B, Affara NI, Coussens LM. Differential macrophage programming in the tumor microenvironment. Trends Immunol. 2012; 33(3):119-126.

8. Hanahan D, Weinberg RA. Hallmarks of cancer: the next generation. Cell. 2011; 144 (5):646-674.

9. Shi C, Pamer EG. Monocyte recruitment during infection and inflammation. Nat Rev Immunol. 2011;11(11):762-74. doi:10.1038/ Nri3070.

10. Taylor PR, Martinez-Pomares L, Stacey M, Lin HH, Brown GD, Gordon S. Macrophage receptors and immune recognition. Annu Rev Immunol. 2005; 23:901-44.

doi:10.1146/annurev.immunol.23. 021704.115816.

11. Chen JJW, Lin YC, Yao PL, Yuan A, Chen HY, Shun CT, et al., Tumorassociated macrophages: the doubleedged sword in cancer progression. J Clin Oncol. 2005; 23 (5):953-64. doi:10.1200/Jco. 2005.12.172. 23.

12. Zhu XD, Zhang JB, Zhuang PY, Zhu HG, Zhang W, Xiong YQ, et al., High expression of macrophage colonystimulating factor in peritumoral liver tissue is associated with poor survival after curative resection of hepatocellular carcinoma. J Clin Oncol. 2008; 26(16): 2707-16. doi:10.1200/Jco.2007.15.6521.

13. Zhou J, Ding T, Pan WD, Zhu LY, Li L, Zheng LM. Increased intratumoral regulatory $\mathrm{T}$ cells are related to intratumoral macrophages and poor prognosis in hepatocellular carcinoma patients. Int J Cancer. 2009; 125(7):1640-8. doi:10.1002/Ijc.24556.

14. Medrek C, Ponten F, Jirstrom K, Leandersson $\mathrm{K}$. The presence of tumor associated macrophages in tumor stroma asaprognostic marker for breast cancer patients. BMC Cancer. 2012; 12: 306. doi:10. 1186/1471-2407-12-306.

15.. Li, C.; Shintani, S.; Terakado, N.; Nakashiro, K.; Hamakawa, H. Infiltration of tumor-associated macrophages in human oral squamous cell carcinoma. Oncol. Rep. 2002, 9, 1219-1223.

16. El-Rouby, D.H. Association of macrophages with angiogenesis in oral verrucous and squamous cell carcinomas. J. Oral Pathol. Med. 2010, 39, 559-564.

17. Mantovani, A.; Sozzani, S.; Locati, M.; Allavena, P.; Sica, A. Macrophage polarization: Tumor-associated macrophages as a paradigm for polarized M2 mononuclear phagocytes. Trends Immunol. 2002, 23, 549-555.

18.. Lau, S.K.; Chu, P.G.; Weiss, L.M. CD163: A specific marker of macrophages in paraffin embedded tissue samples. Am. J. Clin. Pathol. 2004, 122, 794-801.

19.. Li C, Shintani S, Terakado N, Nakashiro $\mathrm{K}$, Hamakawa H. Infiltration of tumorassociated macrophages in human oral squamous cell carcinoma. Oncol Rep 2002; 9(6): 1219-23.

20. Sica A, Schioppa T, Mantovani A, Allavena P. Tumor-associated 
macrophages are a distinct M2 polarized population promoting tumor progression: potential targets of anticancer therapy. Eur J Cancer 2006; 42: 717-27

21. Kazumasa M, Miki H, Jun S, Yoshihiro O. Infiltration of M2 Tumer Associated Macrophages in Oral Squamous Cell Carcinoma Correlates With Tumer Malignancy. Cancer J 2011; 3: 3726-39.

22.. Liu SY, Chang LC, Pan LF, Hung YJ, Lee $\mathrm{CH}$, Shieh YS. Clinicopathologic significance of tumor cell-lined vessel and microenvironment in oral squamous cell carcinoma. Oral Oncol. 2008 Mar;
44(3): 277-85. PubMed PMID: 17475541.

23. Lu C, Huang CS, Tjiu JW, Chiang CP. Infiltrating macrophage count: a significant predictor for the progression and prognosis of oral squamous cell carcinomas in Taiwan. Head Neck. 2010 Jan; 32(1): 18-25. PubMed PMID: 19484765.

24. He $\mathrm{K}$, Zhang $\mathrm{L}$, Huang $\mathrm{CF}$, et al., CD163+ tumor-associated macrophages correlated with poor prognosis and cancer stem cells in oral squamous cell carcinoma. Biomed Res Int. 2014; 2014. PubMed PMID: 24883329.

\section{How to cite this article:}

Ahlam T. Bdewi, Ahmed A. Alkadir Mohamed Labib, Ban F. AL Drobie, Bashar H. Abdullah and Museedi Omar. 2020. Evaluation of CD68 in Oral Squamous Cell Carcinoma and their Relation with Clinicopathological Parameters - An Immunohistochemical Study. Int.J.Curr.Microbiol.App.Sci. 9(07): 3832-3839. doi: https://doi.org/10.20546/ijcmas.2020.907.448 